\title{
Countercurrent Flow Limitation at the Junction between the Surge Line and the Pressurizer of a PWR
}

\author{
Taiga Doi, ${ }^{1}$ Takashi Futatsugi, ${ }^{1}$ Michio Murase, ${ }^{2}$ Kosuke Hayashi, ${ }^{1}$ Shigeo Hosokawa, ${ }^{1}$ \\ and Akio Tomiyama ${ }^{1}$ \\ ${ }^{1}$ Department of Mechanical Engineering, Faculty of Engineering, Kobe University, 1-1 Rokkodai, Nada, Kobe, Hyogo 657-8501, Japan \\ ${ }^{2}$ Institute of Nuclear Technology, Institute of Nuclear Safety System, Inc. (INSS), 64 Sata, Mihama, Fukui 919-1205, Japan
}

Correspondence should be addressed to Akio Tomiyama, tomiyama@mech.kobe-u.ac.jp

Received 13 October 2011; Revised 17 January 2012; Accepted 19 January 2012

Academic Editor: Deendarlianto

Copyright ( 2012 Taiga Doi et al. This is an open access article distributed under the Creative Commons Attribution License, which permits unrestricted use, distribution, and reproduction in any medium, provided the original work is properly cited.

\begin{abstract}
An experimental study on countercurrent flow limitation (CCFL) in vertical pipes is carried out. Effects of upper tank geometry and water levels in the upper and lower tanks on CCFL characteristics are investigated for air-water two-phase flows at room temperature and atmospheric pressure. The following conclusions are obtained: (1) CCFL characteristics for different pipe diameters are well correlated using the Kutateladze number if the tank geometry and the water levels are the same; (2) CCFL occurs at the junction between the pipe and the upper tank both for the rectangular and cylindrical tanks, and CCFL with the cylindrical tank occurs not only at the junction but also inside the pipe at high gas flow rates and small pipe diameters; (3) the flow rate of water entering into the vertical pipe at the junction to the rectangular upper tank is lower than that to the cylindrical tank because of the presence of low frequency first-mode sloshing in the rectangular tank; (4) increases in the water level in the upper tank and in the air volume in the lower tank increase water penetration into the pipe, and therefore, they mitigate the flow limitation.
\end{abstract}

\section{Introduction}

During a PWR plant outage for maintenance and refueling, the reactor coolant is cooled by a residual heat removal (RHR) system. For a certain period, the reactor coolant level is kept around the primary loop center in order to carry out operations like aeration, attachment, or detachment of the steam generator (SG) nozzle dam. This operation mode is called mid-loop operation. If a failure of the RHR system occurs during the mid-loop operation, there is a possibility of boiling of the reactor coolant. One of the effective methods to cool the reactor core in this event is reflux cooling by the SG. During the reflux condensation, steam generated in the reactor core and water condensed in a pressurizer due to heat transfer to its vessel wall may form a countercurrent flow in a surge line connecting the hot leg and the pressurizer. The ROSA-IV/LSTF (Rig-of-Safety-Assessment No. 4/Large Scale Test Facility) experiment [1] for the loss of RHR systems during mid-loop operation showed that water accumulates in the pressurizer due to the limitation of liquid flow in the countercurrent flow in the surge line. Thus, understanding the characteristics of countercurrent flow limitation (CCFL) in the surge line is of great importance for safety evaluation of the mid-loop operation.

In our previous study [2], countercurrent flow limitation (CCFL) in a scale-down model of a PWR surge line, which consists of a vertical pipe and an inclined pipe with several elbows, was investigated by measuring the relationship between the water and gas flow rates in the surge line. The relationship is referred to as CCFL characteristics. The CCFL takes place at three locations in the experiments, that is, at the junction between the vertical pipe and the bottom of the pressurizer, in the inclined pipe and at the junction between the inclined pipe and the hot leg. The CCFL characteristics strongly depend on the location of CCFL. The experiments imply that the CCFL at the junction between the vertical pipe and the bottom of the pressurizer plays an important role in the actual surge line under the reflux cooling.

Many studies on CCFL in vertical pipes have been carried out [3-11] using the experimental apparatus consisting of a 


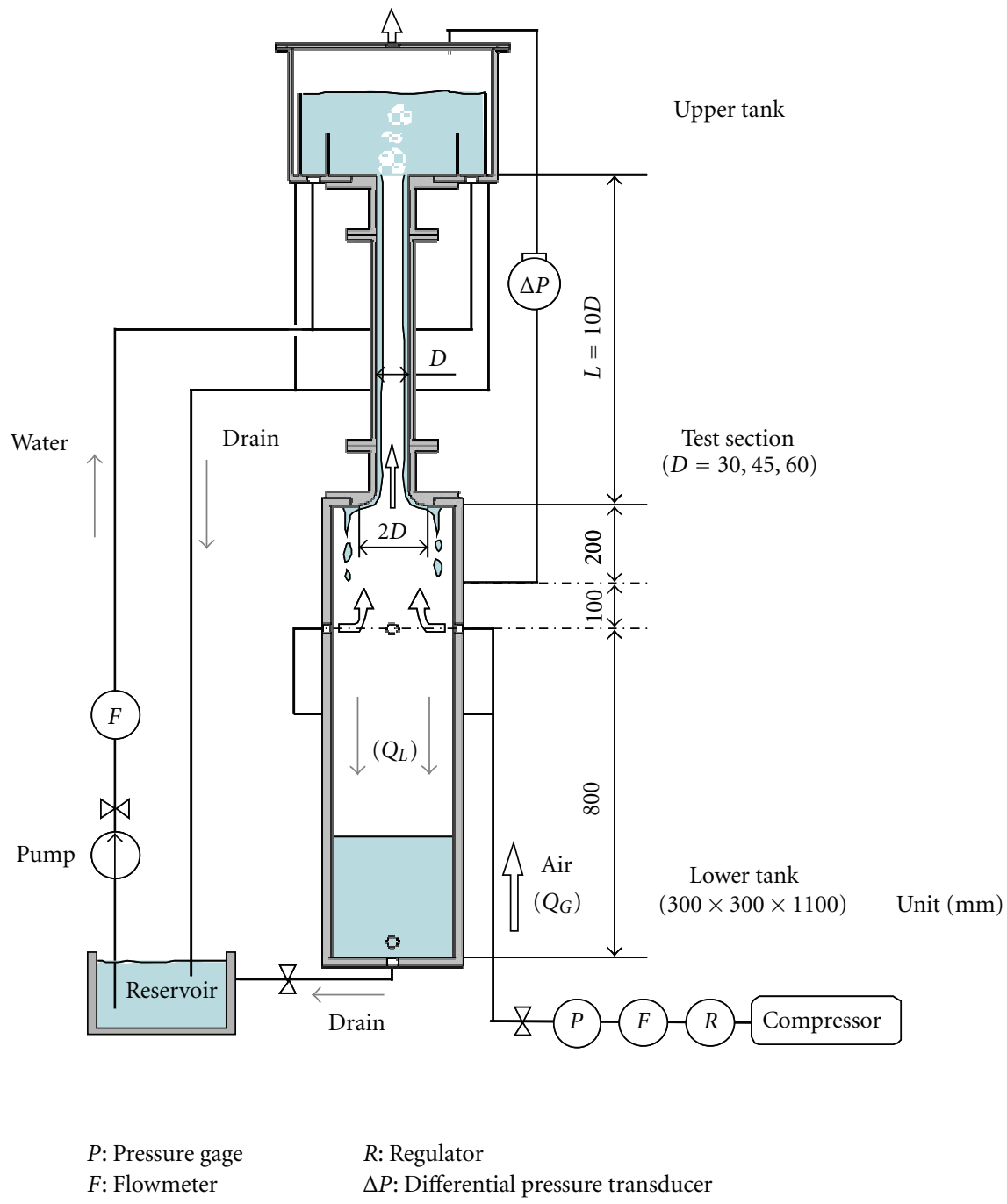

Figure 1: Experimental setup.

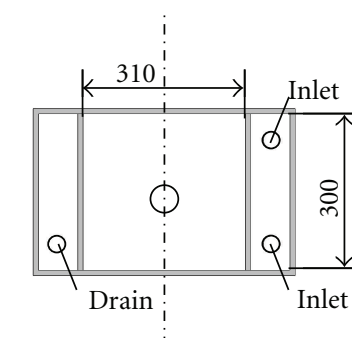

Separator board

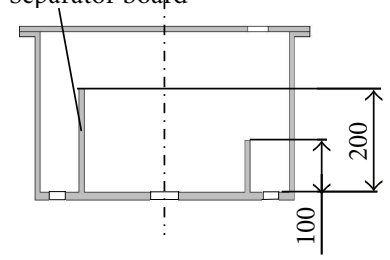

(a) Rectangular tank

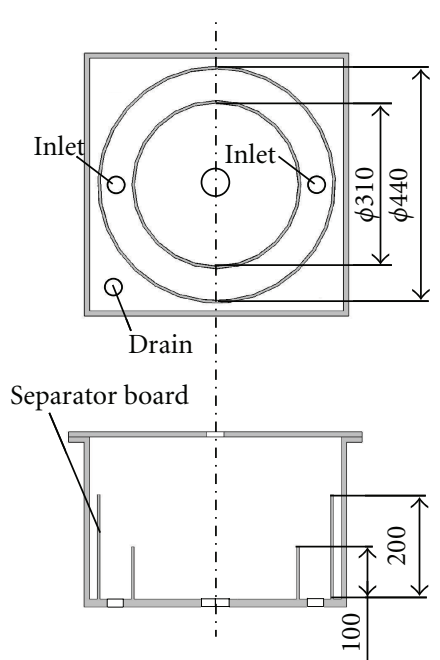

(b) Cylindrical tank (a)

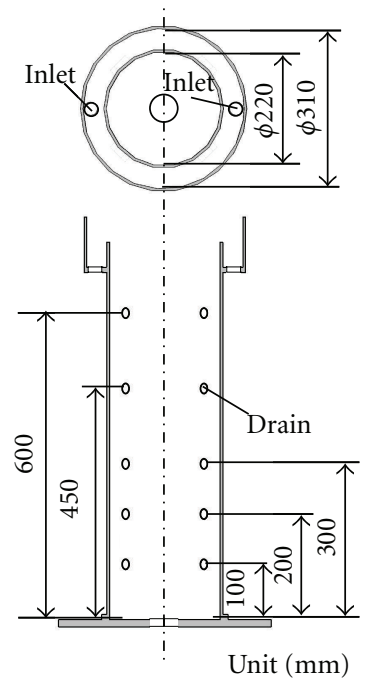

(c) Cylindrical tank (b)

Figure 2: Upper tanks. 


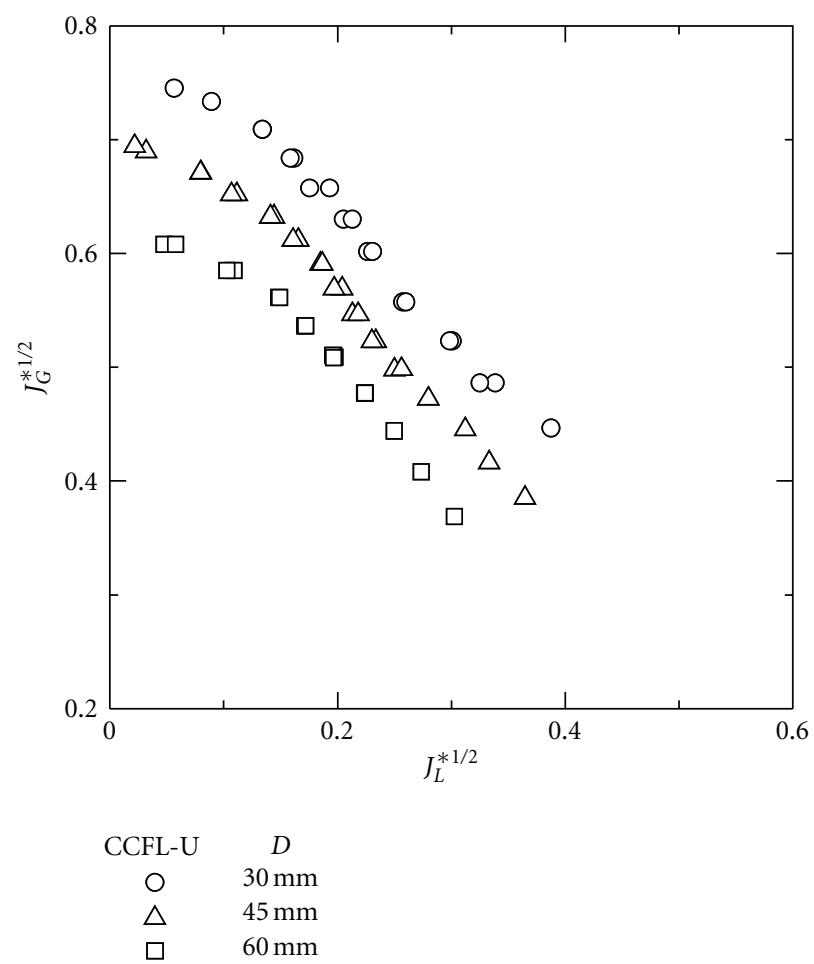

(a) Rectangular tank

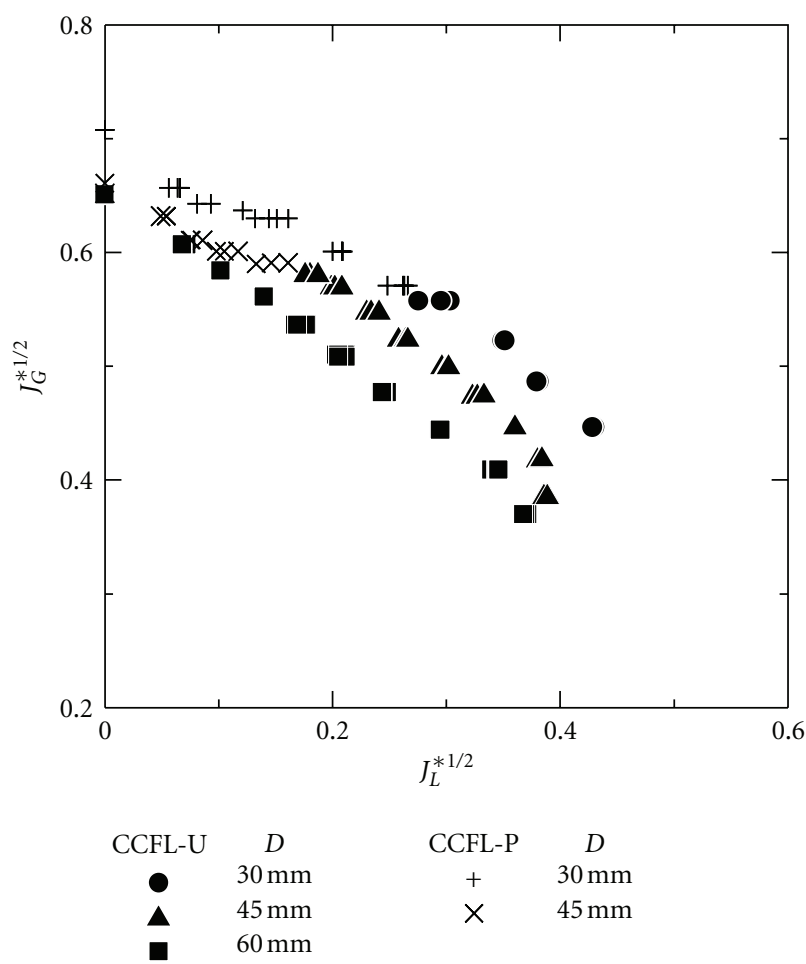

(b) Cylindrical tank (a)

FIGURE 3: CCFL characteristics for rectangular and cylindrical tanks on $J_{G}{ }^{* 1 / 2}-J_{L}{ }^{* 1 / 2}$ plane.

vertical pipe, an upper tank, and a lower tank. Although a number of experimental data of CCFL for various diameters, lengths, and end geometries of vertical pipes have been obtained [9-11], modeling of CCFL in vertical pipes is insufficient because of a large scatter in the data obtained for the different experiments. This scatter implies that the upper and lower tank geometries may have nonnegligible influence on CCFL. Little has, however, been studied on the effect of tank geometry.

In the present study, the effects of upper tank geometry on CCFL characteristics were investigated by using a rectangular tank and a cylindrical tank. The flow rate of water entering into a lower tank was measured to obtain the CCFL characteristics. Flow patterns in the upper tanks were observed by using a high-speed video camera and the pressure difference between the upper and lower tanks was measured to understand relations between CCFL characteristics and flow patterns in the tanks. Furthermore effects of water levels in the cylindrical upper tank and the lower tank on CCFL characteristics were investigated.

\section{Experimental}

2.1. Experimental Setup. Figure 1 shows the experimental setup. It consists of the upper tank, which corresponds to the bottom part of the pressurizer, the vertical pipe corresponding to a part of the surge line, the lower tank, the air supply system, and the water supply system. The pipe and tanks are made of transparent acrylic resin for observation. The diameters, $D$, of vertical pipes are 30,45 , and $60 \mathrm{~mm}$. Air was supplied from the oil-free compressor (SRL-11P6AI, Hitachi Ltd.) and flowed into the lower tank from four inlets through the regulator (R600-20, CKD) and the flowmeter (FLT, Flowcell, Ltd.). Tap water was supplied using the magnet pump (MX-F400, Iwaki, Ltd.) and flowed into the upper tank through the flowmeter (FLT-N, Flowcell, Ltd.). Experiments were carried out at room temperature and atmospheric pressure. It is well known that CCFL occurrence is strongly influenced by junction geometry, for example, the liquid flow rate with a sharp-edged junction is lower than that with a round-edged junction $[12,13]$. The right-angle junction is used for the junction between the upper tank and the vertical pipe to obtain flow limitation at that junction, whereas the bell-mouth junction is used for the junction between the lower tank and the pipe to prevent liquid flow limitation at that junction.

Three types of upper tanks, which we refer to as the rectangular tank, cylindrical tank (a), and cylindrical tank (b), are shown in Figures 2(a), 2(b), and 2(c), respectively. The cylindrical tank (a) and the rectangular tank were used to investigate the effects of upper tank geometry on CCFL characteristics. Water levels in the upper tanks were kept constant by overflowing the supplied water. The effects of water level were investigated by using the cylindrical tank (b). The ratio of its diameter to the pipe diameter was determined so as to be analogous to the actual pressurizer. It has drain 


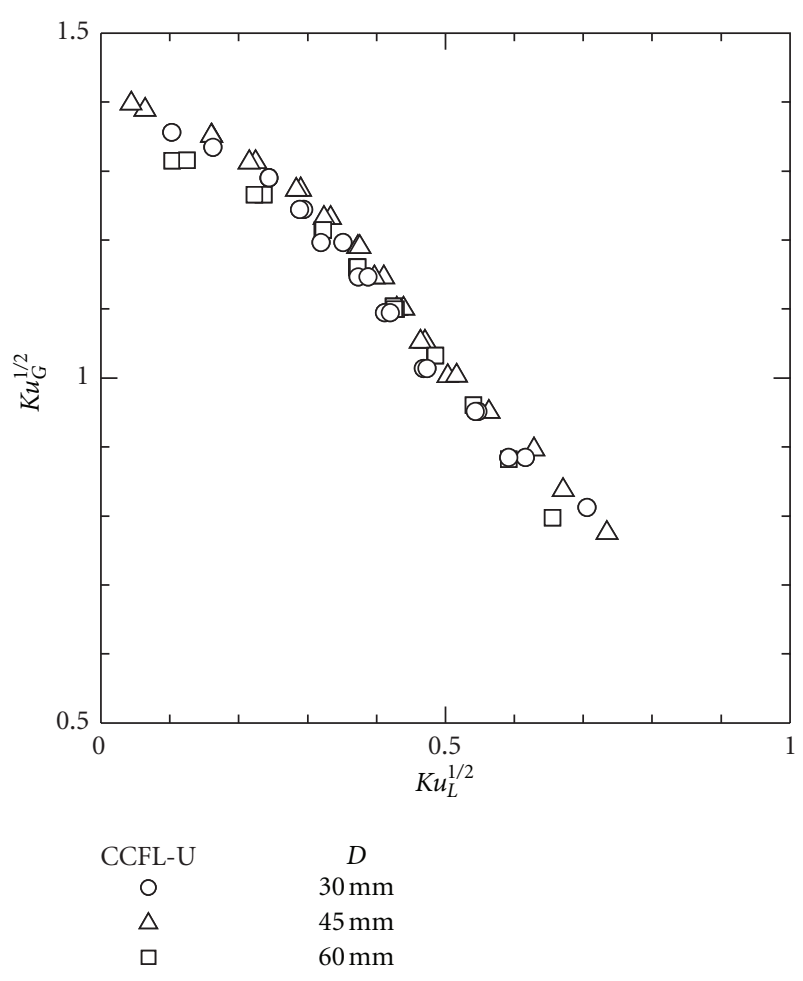

(a) Rectangular tank

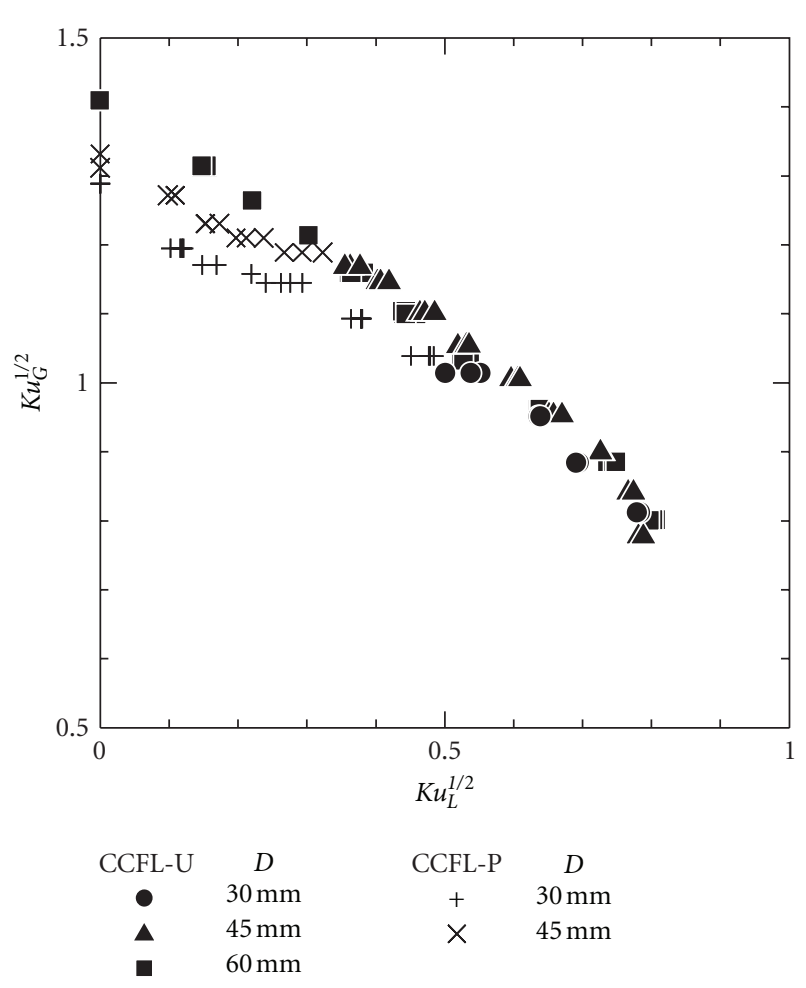

(b) Cylindrical tank (a)

FIGURE 4: CCFL characteristics for rectangular and cylindrical tanks on $K u_{G}{ }^{* 1 / 2}-K u_{L}{ }^{* 1 / 2}$ plane.

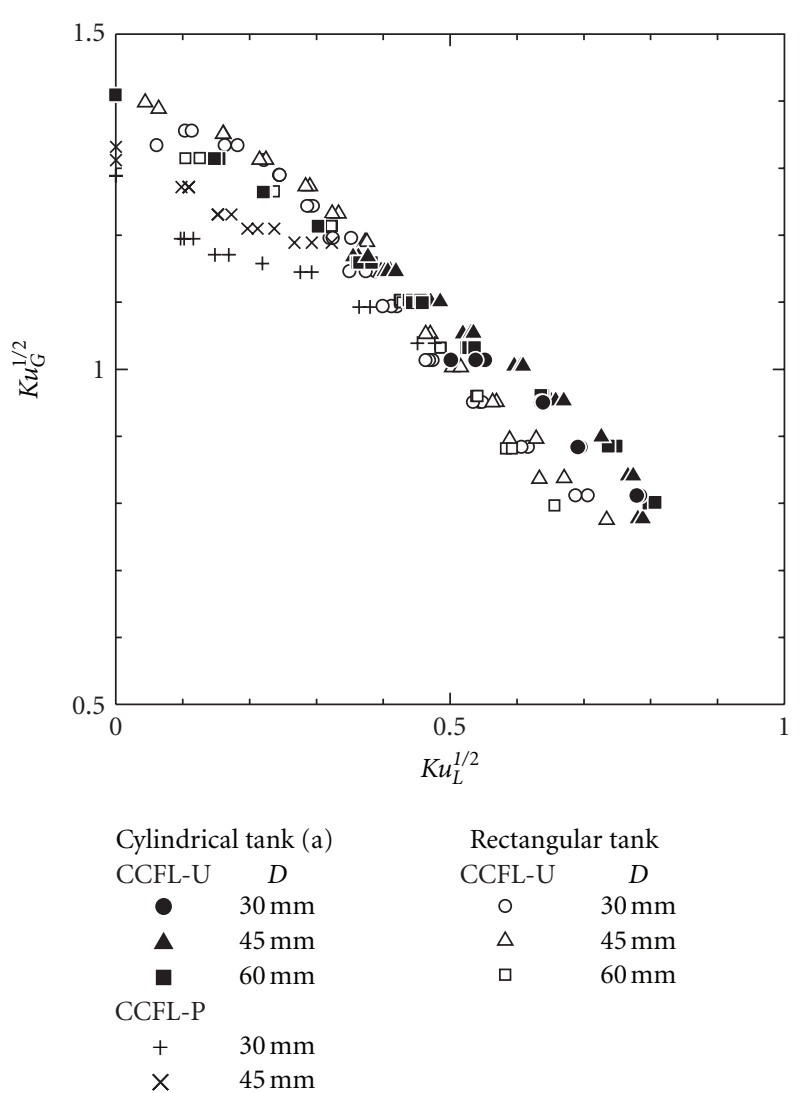

FIGURE 5: Effects of upper tank geometry on CCFL characteristics.

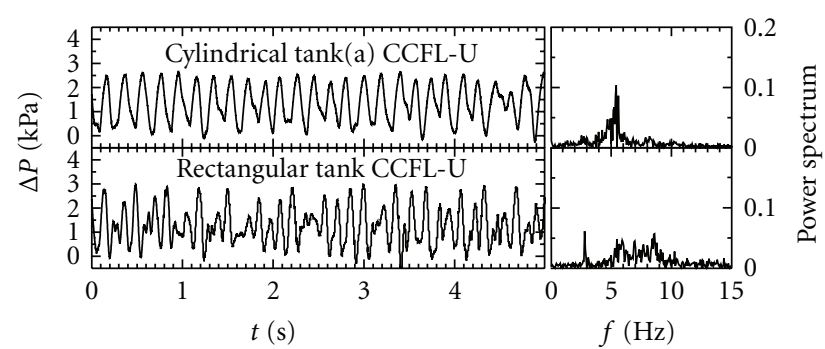

(a) $J_{G}=4.8 \mathrm{~m} / \mathrm{s}\left(K u_{G}{ }^{1 / 2}=1.00\right)$

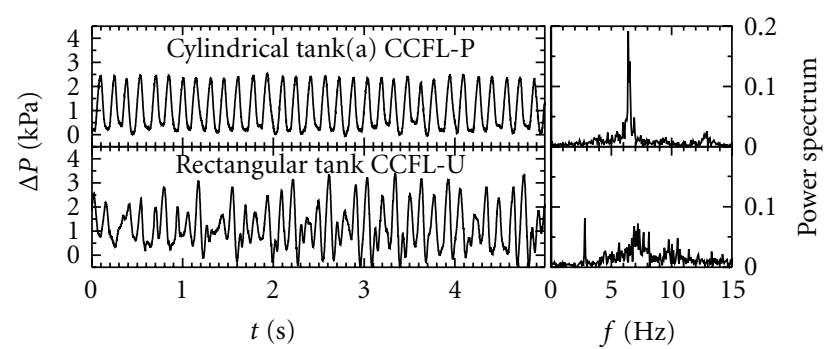

(b) $J_{G}=7.3 \mathrm{~m} / \mathrm{s}\left(K u_{G}^{1 / 2}=1.23\right)$

Figure 6: Pressure difference $\Delta P$ between upper and lower tanks $(D=45 \mathrm{~mm})$. 

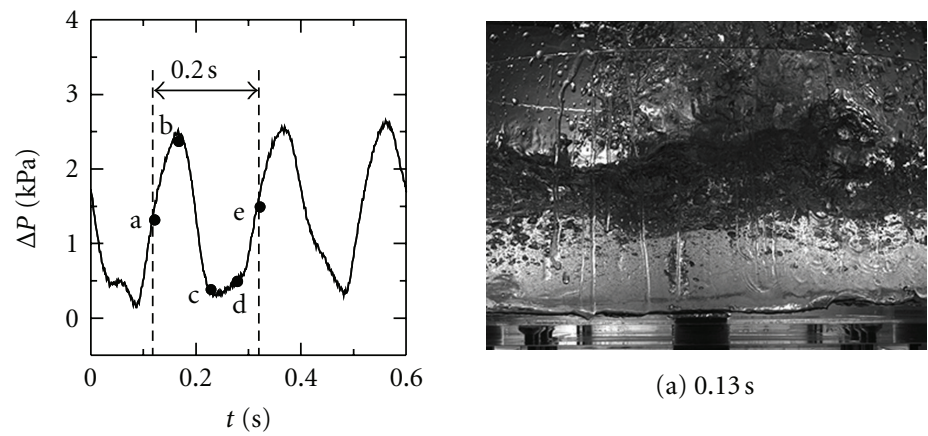

(a) $0.13 \mathrm{~s}$

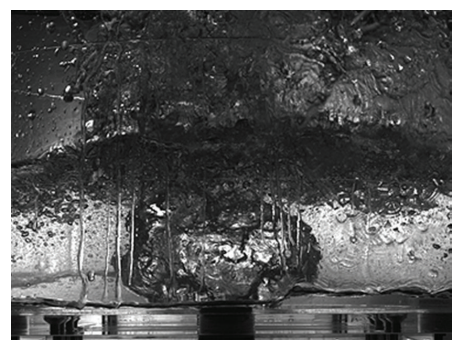

(c) $0.23 \mathrm{~s}$

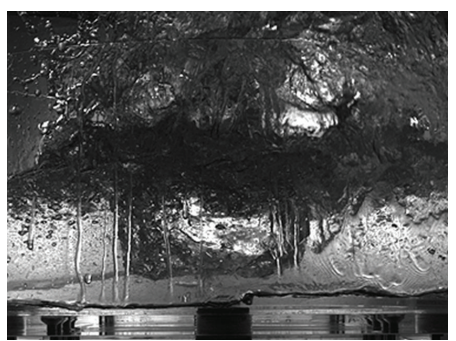

(d) $0.28 \mathrm{~s}$

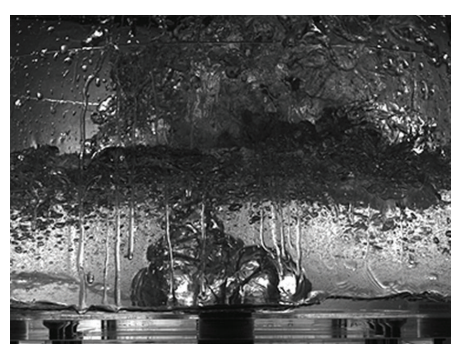

(b) $0.18 \mathrm{~s}$

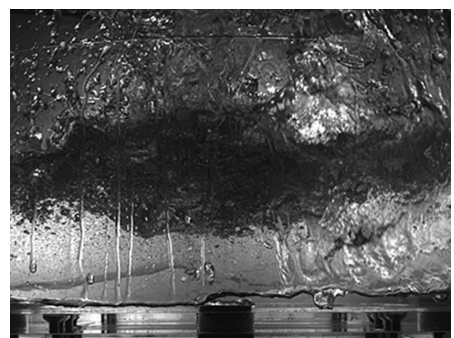

(e) $0.33 \mathrm{~s}$

Figure 7: Bubble generation process in the cylindrical tank (a) $\left(J_{G}=4.9 \mathrm{~m} / \mathrm{s}, J_{G}{ }^{* 1 / 2}=0.50, K u_{G}{ }^{1 / 2}=1.0\right.$, and $D=45 \mathrm{~mm}$ ).

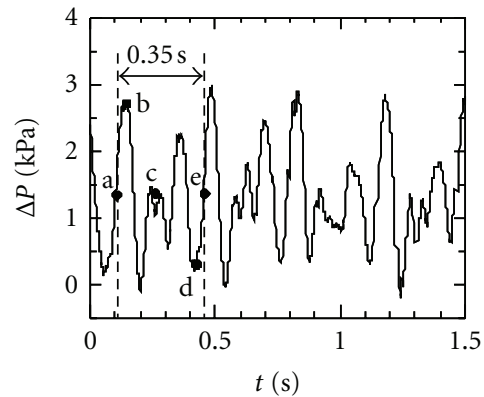

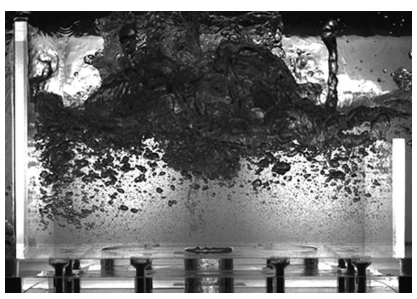

(a) $0.1 \mathrm{~s}$

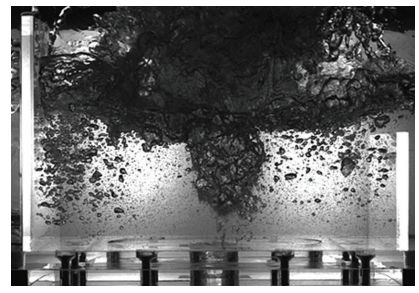

(d) $0.42 \mathrm{~s}$

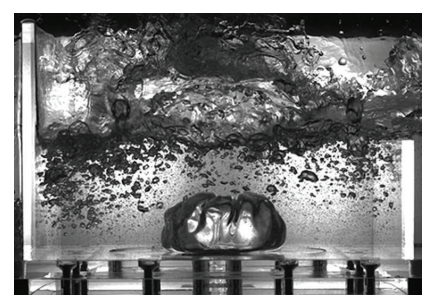

(b) $0.15 \mathrm{~s}$

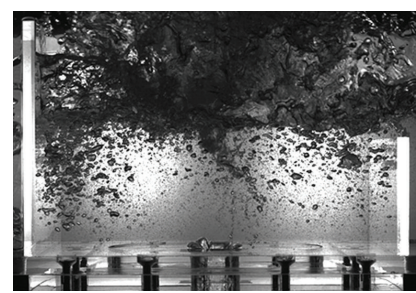

(e) $0.45 \mathrm{~s}$

FigURE 8: Bubble generation process in the rectangular tank $\left(J_{G}=4.9 \mathrm{~m} / \mathrm{s}, J_{G}{ }^{* 1 / 2}=0.50, K u_{G}{ }^{1 / 2}=1.0\right.$, and $\left.D=45 \mathrm{~mm}\right)$.

holes on its wall at various elevations. The drain holes used in each experiment were changed to test various water levels in the upper tank.

\subsection{Experimental Method}

2.2.1. CCFL Characteristics. CCFL characteristics were investigated by measuring the time-averaged flow rate, $Q_{L}$, of water entering into the lower tank at constant gas flow rates, $Q_{G}$. The $Q_{L}$ was calculated from the rise speed of water level in the lower tank. The ranges of the liquid and gas volume fluxes, $J_{L}$ and $J_{G}$, tested were $0 \leq J_{L} \leq 0.118 \mathrm{~m} / \mathrm{s}$ and $2.40 \leq$ $J_{G} \leq 16.4 \mathrm{~m} / \mathrm{s}$, respectively, where $J_{L}$ and $J_{G}$ are defined by

$$
J_{k}=\frac{Q_{k}}{A} \quad(k=L, G)
$$

Here $A$ is the cross-sectional area of the vertical pipe and the subscripts $L$ and $G$ denote the liquid and gas phases, respectively. The uncertainties in measured $J_{L}$ and $J_{G}$ estimated at $95 \%$ confidence were $\pm 3.0 \%$ and $\pm 2.5 \%$, respectively. 


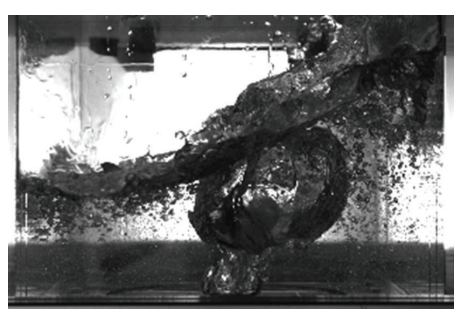

(a) $0 \mathrm{~s}$

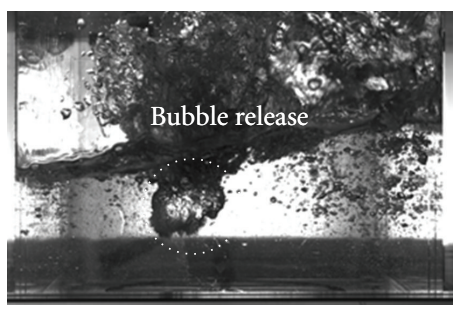

(b) $0.18 \mathrm{~s}$

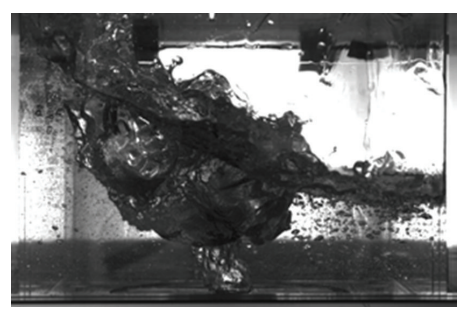

(c) $0.35 \mathrm{~s}$

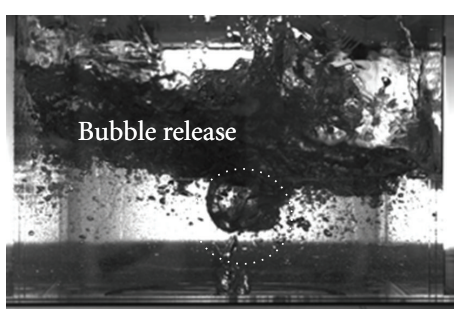

(d) $0.53 \mathrm{~s}$

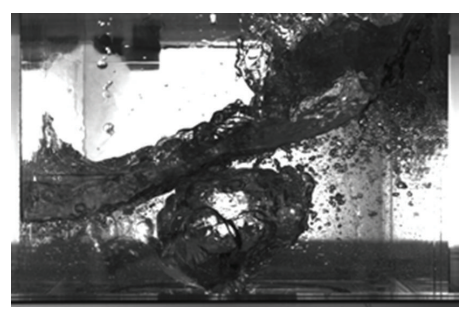

(e) $0.73 \mathrm{~s}$

FIGURE 9: First-mode sloshing in the rectangular tank $\left(J_{G}=7.7 \mathrm{~m} / \mathrm{s}, J_{G}{ }^{* 1 / 2}=0.70, K u_{G}{ }^{1 / 2}=1.3\right.$, and $\left.D=30 \mathrm{~mm}\right)$.

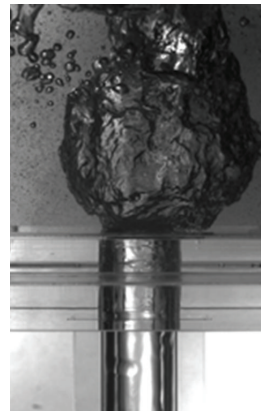

$0 \mathrm{~s}$

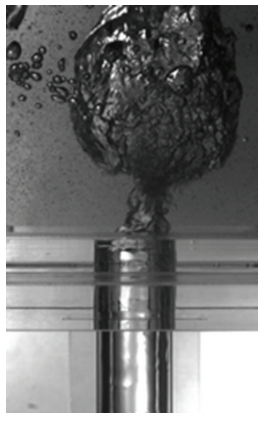

$0.02 \mathrm{~s}$

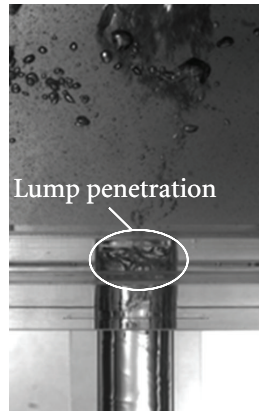

$0.04 \mathrm{~s}$

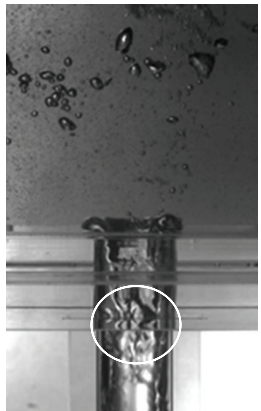

$0.06 \mathrm{~s}$

FIGURE 10: Relation between bubble release and water penetration $\left(J_{G}=5.8 \mathrm{~m} / \mathrm{s}, J_{G}{ }^{* 1 / 2}=0.60, K u_{G}{ }^{1 / 2}=1.1\right.$, and $\left.D=30 \mathrm{~mm}\right)$.

2.2.2. Pressure Difference. The pressure difference $\Delta P$ $\left(=P_{\text {Lower }}-P_{\text {Upper }}\right.$, where $P_{\text {Lower }}$ and $P_{\text {Upper }}$ are the pressures in the lower and upper tanks, resp.) was measured using a differential pressure transducer (DP45, Valydine, Ltd. natural frequency $>600 \mathrm{~Hz}$ ). It was connected between the top of the upper tank and the side wall of the lower tank as shown in Figure 1. The sampling rate was $1.0 \mathrm{kHz}$, and the measurement time was 30 seconds. The uncertainty in measured $\Delta P$ was less than $0.5 \%$ of the full scale $(6 \mathrm{kPa})$. Flows in the upper tank were observed by using a highspeed video camera (Dantec Dynamics, Nano sence Mk3) to understand the relation between $\Delta P$ and the flow behavior in the upper tank. The frame rate was $100 \mathrm{fps}$ and the recording time was $30 \mathrm{~s}$.

\section{Results and Discussion}

3.1. Effects of Upper Tank Geometry. Flow visualization with the high-speed video camera showed that, under all the test conditions, the CCFL with the rectangular tank occurred only at the junction between the vertical pipe and the upper tank, that is, some water flows into the pipe from the upper tank, but the remaining water does not and returns to the reservoir, and then the water entering the pipe forms liquid film and flows down to the lower tank without flooding in the pipe. This CCFL taking place at the upper junction is referred to as CCFL-U. The CCFL characteristics measured using the rectangular tank are plotted in Figure 3(a), where $J_{L}{ }^{*}$ and $J_{G}{ }^{*}$ are the Wallis parameters [14] defined by

$$
J_{k}^{*}=J_{k}\left[\frac{\rho_{k}}{g D\left(\rho_{L}-\rho_{G}\right)}\right]^{1 / 2} \quad(k=L, G),
$$

where $\rho$ is the density, $g$ the acceleration of gravity and $D$ the pipe diameter. At constant $J_{G}{ }^{*}, J_{L}{ }^{*}$ becomes smaller with increasing $D$, that is, the flow limitation becomes stronger. Figure 3(b) shows the CCFL characteristics for the cylindrical tank (a). The CCFL occurs only at the junction at low $J_{G}{ }^{*}$, whereas at high $J_{G}{ }^{*}$ and $D \leq 45 \mathrm{~mm}$, some water penetrating into the vertical pipe intermittently flowed back into the upper tank due to flooding, that is, the CCFL occurs not only at the junction but also inside the pipe. This CCFL is referred to as CCFL-P. Thus, the CCFL characteristics clearly 

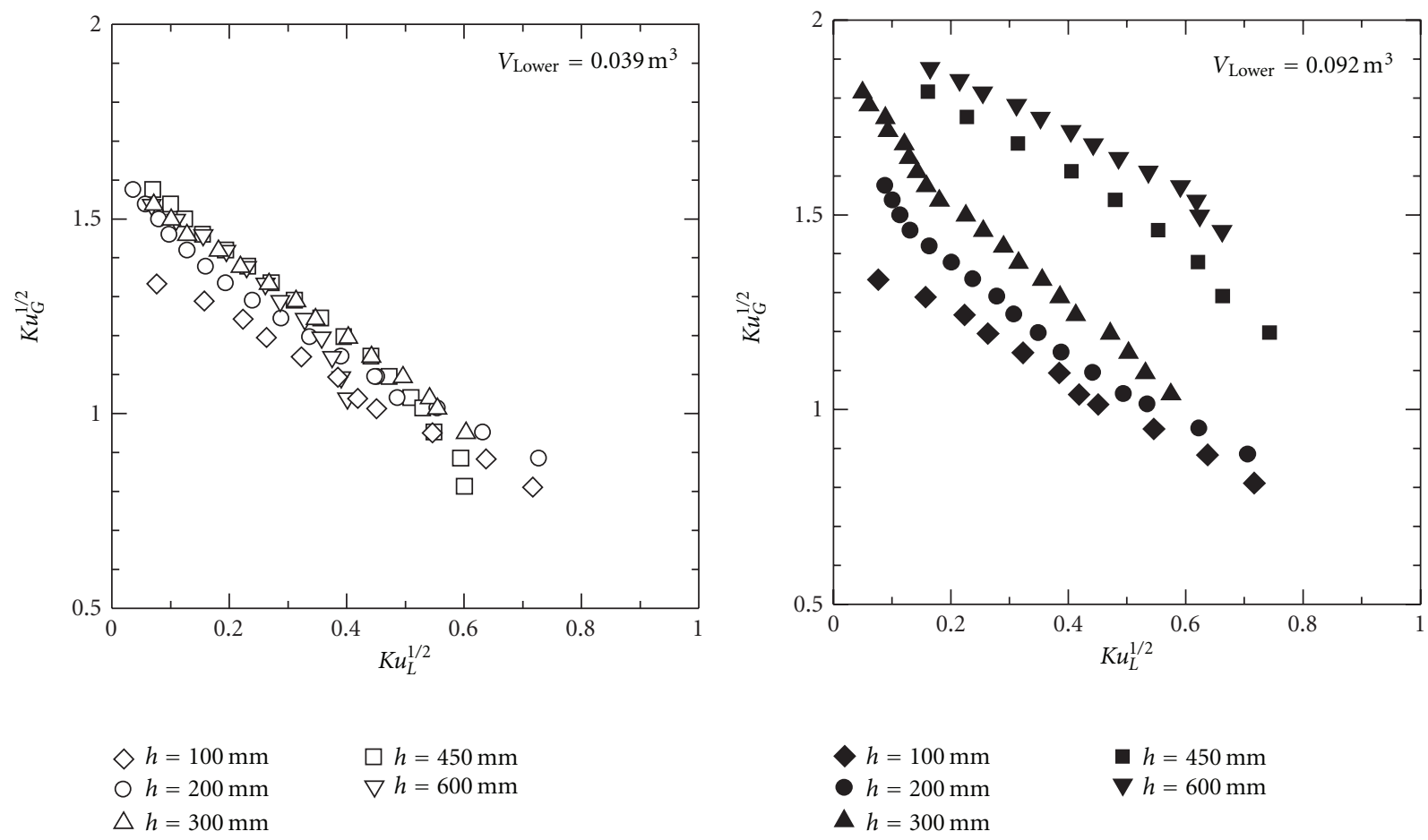

(a)

(b)

Figure 11: Effects of water level, $h$, in upper tank on CCFL characteristics $(D=30 \mathrm{~mm})$.

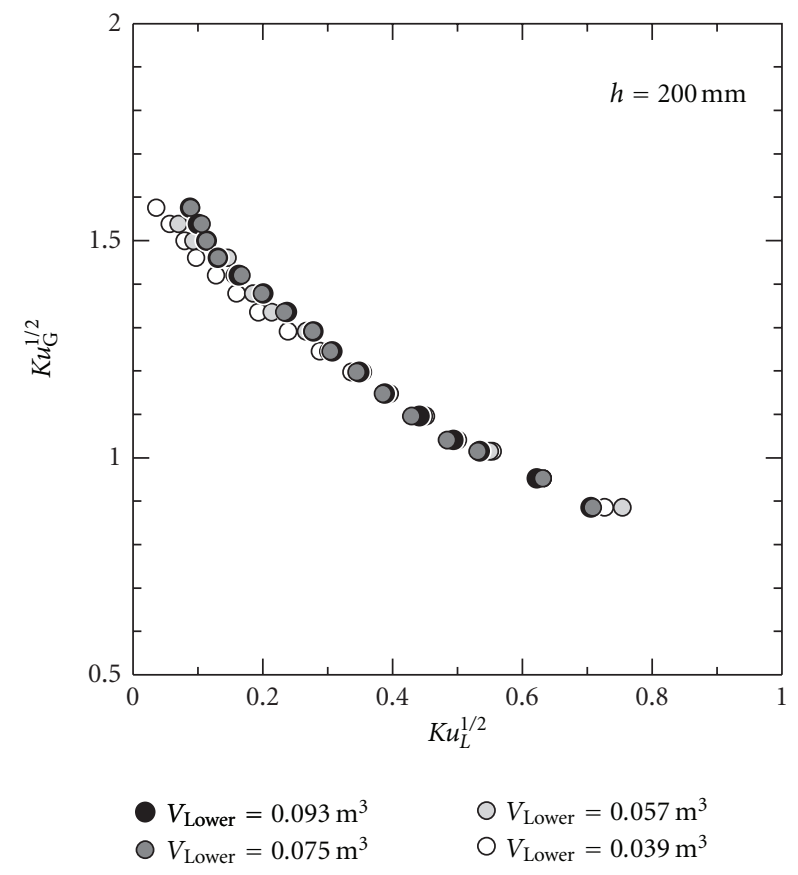

(a)

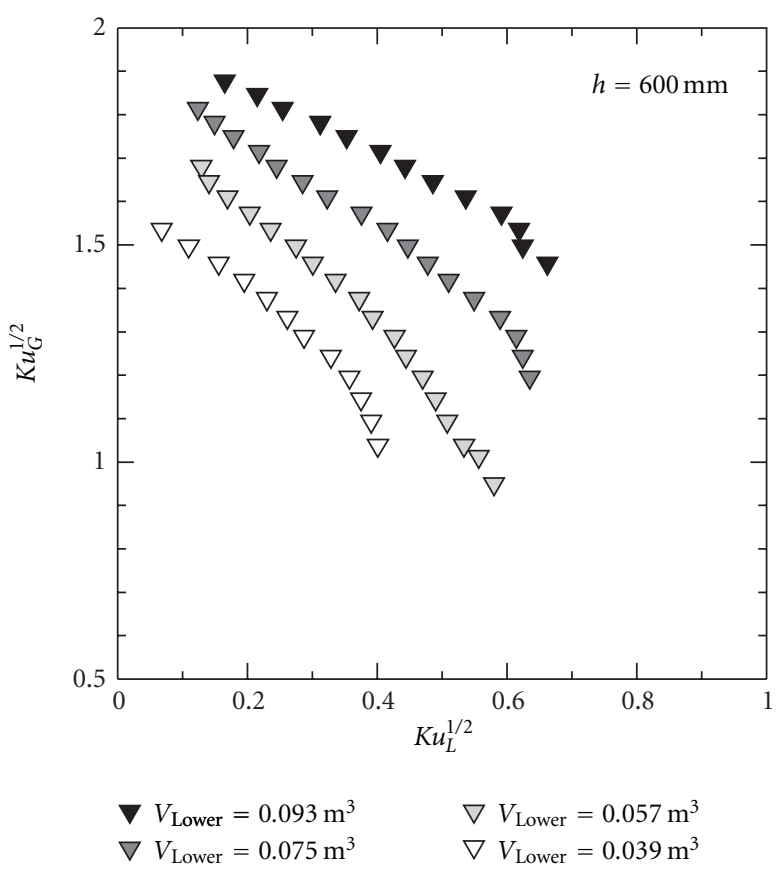

(b)

FIgURE 12: Effects of air volume, $V_{\text {Lower }}$, in lower tank on CCFL characteristics $(D=30 \mathrm{~mm})$. 


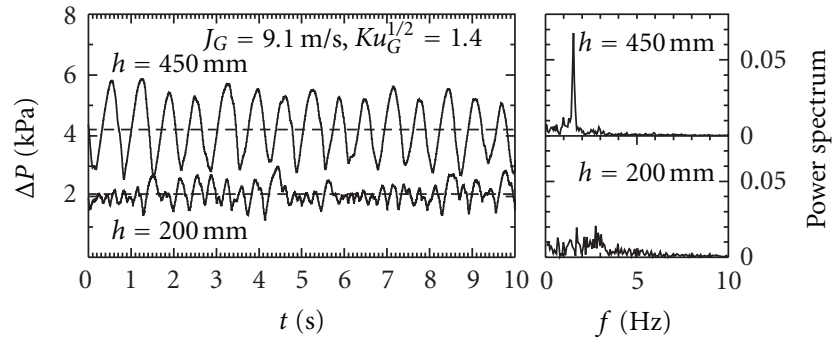

Figure 13: Pressure difference $\Delta P$ between upper and lower tanks (Cylindrical tank (b), $D=30 \mathrm{~mm}, V_{\text {Lower }}=0.092 \mathrm{~m}^{3}$ and $J_{G}=$ $9.1 \mathrm{~m} / \mathrm{s}$ ).

depend on the pipe diameter and the location where CCFL takes place.

Richter [7] and Jayanti et al. [15] suggested that, for prediction of flooding, the Wallis parameter, $J^{*}$, is appropriate for small diameter pipes, whereas the Kutateladze number, $K u$, [16] is better for large diameter pipes. Vijayan et al. [17] carried out flooding experiments using vertical pipes of $D=$ 25,67 , and $99 \mathrm{~mm}$ and confirmed that $J^{*}$ is better for small $D(25 \mathrm{~mm})$, whereas $K u$ is better for large $D(67$ and $99 \mathrm{~mm})$. The Kutateladze number is defined by

$$
K u_{k}=J_{k}\left[\frac{\rho_{k}^{2}}{g \sigma\left(\rho_{L}-\rho_{G}\right)}\right]^{1 / 4} \quad(k=L, G),
$$

where $\sigma$ is the surface tension. The Wallis parameter includes $D$ but the Kutateladze number does not. Therefore, the pipe diameter plays an important role in flooding for small $D$, whereas the mechanism of flooding is less dependent on $D$ in large pipes. The CCFL characteristics are replotted on the $K u_{L}{ }^{1 / 2}-K u_{G}{ }^{1 / 2}$ plane as shown in Figure 4. The CCFL characteristics for different pipe diameters are well correlated with the Kutateladze numbers both for the rectangular and cylindrical tanks when the CCFL occurs only at the junction (CCFL-U). Therefore, the diameter effect on the CCFL characteristics is not so significant in these cases. The CCFL characteristics for the two tanks are compared in Figure 5. The flow limitation with the cylindrical tank (a) is stronger than that with the rectangular tank at high $K u_{G}$ because of the CCFL occurrence inside the pipe. On the other hand, at low $K u_{G}$, the CCFL with the rectangular tank is stronger. This will be discussed later based on the observation of bubble motions in the upper tanks.

Figure 6 shows the pressure differences, $\Delta P$, for the cylindrical and rectangular tanks and their power spectrums obtained by the fast Fourier transform analysis. The pressure fluctuations for the cylindrical tank (a) mainly consist of waves in the range of $5-7 \mathrm{~Hz}$. On the other hand, those for the rectangular tank consist of single peaks at $3 \mathrm{~Hz}$ and broad peaks in the range of $5-10 \mathrm{~Hz}$. Figure 7 shows a typical bubble generation process in the cylindrical tank (a) and $\Delta P$ at $J_{G}=4.9 \mathrm{~m} / \mathrm{s}$ and $D=45 \mathrm{~mm}$. There is no bubble at the junction at $t=0.13 \mathrm{~s}$. The $\Delta P$ increases as a bubble starts to be generated at the junction until $t=0.18 \mathrm{~s}$. The $\Delta P$ then decreases as the bubble grows for $t=0.18-0.23 \mathrm{~s}$. The bubble is released from the junction at $t=0.28 \mathrm{~s}$, and then, the next bubble starts to be generated at $0.33 \mathrm{~s}$. The period and the frequency of this process are about $0.20 \mathrm{~s}$ and $5 \mathrm{~Hz}$, which corresponds to the peak frequency.

A bubble generation process in the rectangular tank at $J_{G}=4.9 \mathrm{~m} / \mathrm{s}$ and $D=45 \mathrm{~mm}$ is shown in Figure 8 . The $\Delta P$ increases as the bubble grows at the junction for $t=$ $0.10-0.15 \mathrm{~s}$. For $t>0.15 \mathrm{~s}$, a trailing bubble is formed behind the leading bubble. The fluctuation of $\Delta P$ for $0.15<$ $t<0.42 \mathrm{~s}$ must be due to these trailing bubbles. The next leading bubble starts to grow at $t=0.45 \mathrm{~s}$. The period of the generation of leading bubbles is $0.35 \mathrm{~s}$. The single peak at $3 \mathrm{~Hz}$ and the broad peak in the range of $5-10 \mathrm{~Hz}$ in Figure 5, therefore, correspond to the leading-bubble generation cycle and the fluctuation due to the trailing bubbles, respectively. The first mode sloshing shown in Figure 9 was observed only for the rectangular tank. The free surface in the tank took the maximum inclination at $t=0 \mathrm{~s}$ as shown in Figure 9(a). Then the water moved to the left side, and the bubble was detached from the junction due to water movement in the horizontal direction (Figure 9(b)). Two leading bubbles were released during one period of the sloshing (Figures 9(a)$9(\mathrm{e}))$. The natural frequency of the first mode sloshing in a two-dimensional rectangular tank is given by [18]

$$
f=\frac{\sqrt{g k \tanh k H}}{2 \pi} \quad\left(k=\frac{\pi}{L}\right),
$$

where $H$ is the height of the free surface and $L$ the width of the tank. According to (4), the frequency for the rectangular tank used is $1.53 \mathrm{~Hz}$, which is about half of the bubble release frequency. The bubble release frequency is, therefore, strongly governed by the sloshing in the tank.

Figure 10 shows images of flows in the rectangular tank and the pipe. Water lump penetrated into the pipe when a bubble detached. The CCFL is, therefore, mitigated when the bubble release frequency is high. This might be the main reason why the CCFL with the rectangular tank is stronger than that with the cylindrical tank (a) at low $K u_{G}$ as shown in Figure 5.

3.2. Effects of Water Level in Tank. The CCFL characteristics measured using the cylindrical tank (b) shown in Figure 2(c) are discussed in this section. Various water levels in the upper and the lower tanks were tested. The water level in the lower tank was kept constant throughout each experiment by manually controlling the drain cock opening. In this case, $Q_{L}$ was calculated from the amount of drain water. Figure 11 shows the CCFL characteristics for various water levels in the upper tank at constant water levels in the lower tank, where $V_{\text {Lower }}$ is the air volume in the lower tank and $h$ the elevation of the drain holes in the upper tank. The CCFL becomes stronger as $h$ decreases at $V_{\text {Lower }}=0.039 \mathrm{~m}^{3}$. The difference in the CCFL characteristics is, however, not so significant. On the other hand, the CCFL characteristics strongly depend on $h$ at $V_{\text {Lower }}=0.092 \mathrm{~m}^{3}$. Effects of $V_{\text {Lower }}$ are shown in Figure 12. The CCFL characteristics do not depend on $V_{\text {Lower }}$ at $h=200 \mathrm{~mm}$, whereas the influence of $V_{\text {Lower }}$ is significant at $h=600 \mathrm{~mm}$, that is, the increase in $V_{\text {Lower }}$ mitigates the CCFL. 


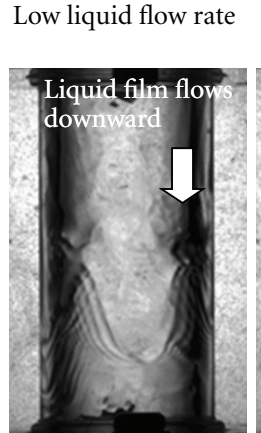

$0.3 \mathrm{~s}$

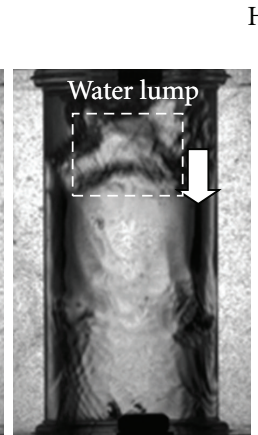

$0.32 \mathrm{~s}$
High liquid flow rate

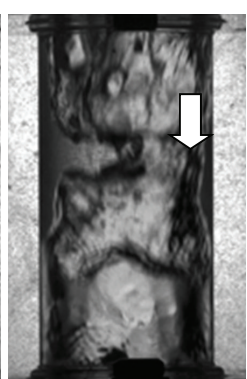

$0.34 \mathrm{~s}$

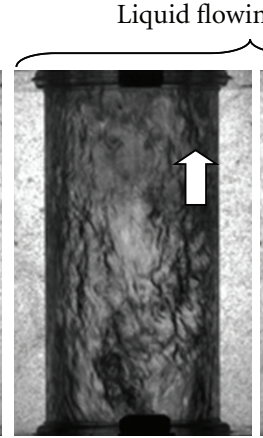

$0.61 \mathrm{~s}$
Liquid flowing back

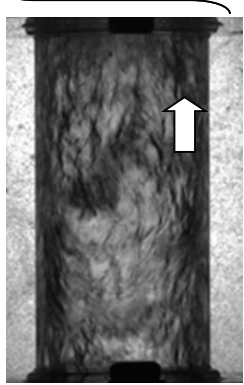

$0.63 \mathrm{~s}$
Low liquid flow rate

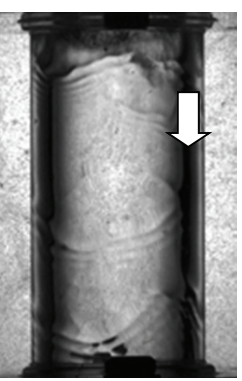

$0.98 \mathrm{~s}$

FIgure 14: Flow patterns at the middle of the vertical pipe (Cylindrical tank (b), $D=30 \mathrm{~mm}, h=450 \mathrm{~mm}, V_{\text {Lower }}=0.092 \mathrm{~m}^{3}$, and $\left.J_{G}=9.1 \mathrm{~m} / \mathrm{s}\right)$.

Figure 13 shows the pressure differences for the cylindrical tank (b) and their power spectrums. The time-averaged $\Delta P$ increases with the water level in the upper tank, which corresponds to the water head in the upper tank. The amplitude of the pressure fluctuation at $h=450 \mathrm{~mm}$ is larger than that at $h=200 \mathrm{~mm}$, and the fluctuation frequency at $h=450 \mathrm{~mm}$ is lower than that at $h=200 \mathrm{~mm}$. Images of flow patterns in the middle part of the vertical pipe for $h=450 \mathrm{~mm}$ and $V_{\text {Lower }}=0.039 \mathrm{~m}^{3}$ are shown in Figure 14 . The amount of falling liquid film is small at $t=0.30 \mathrm{~s}$. The large water lump falls for $0.32<t<0.34 \mathrm{~s}$. The $\Delta P$ increases during the water lump falling. Then the liquid film flows back to the upper tank and the $\Delta P$ decreases. The liquid film restarts to fall at $t=0.98 \mathrm{~s}$. The amount of the falling water lump is small at low $h$ and low $V_{\text {Lower }}$, and it becomes larger as $h$ and $V_{\text {Lower }}$ increase. This is the main cause of the difference in the CCFL characteristics for different values of $h$ and $V_{\text {Lower }}$.

\section{Conclusions}

Countercurrent flow limitation (CCFL) in vertical pipes are measured using an apparatus consisting of the vertical pipe, the upper tank, and the lower tank to understand effects of tank geometry and water level in the tanks. The tank shapes used were rectangular and cylindrical. The pipe diameters tested were 30,45 , and $60 \mathrm{~mm}$. Air and water at room temperature and atmospheric pressure were supplied from the upper tank and from the lower tank, respectively. The flow rate of water entering into the lower tank was measured to obtain CCFL characteristics. Flow patterns in the upper tanks were observed by using a high-speed video camera and pressure differences between the upper and lower tanks were measured to understand relations between CCFL characteristics and the flow patterns in the tanks. The main conclusions obtained under the present experimental conditions are as follows.

(1) The CCFL characteristics for different pipe diameters are well correlated using the Kutateladze number if the tank geometry and the water levels in the tanks are the same.
(2) CCFL takes place at the junction between the pipe and the upper tank both for the rectangular and cylindrical tanks. In addition, CCFL with the cylindrical tank (a) takes place not only at the junction but also inside the pipe when the gas flow rate is high and the pipe diameter is small.

(3) The flow rate of water entering into the vertical pipe at the junction for the rectangular upper tank is lower than that for the cylindrical tank (a) because of the presence of low frequency first-mode sloshing in the rectangular tank.

(4) Water penetration into the pipe increases with the water level, $h$, in the cylindrical upper tank and the air volume, $V_{\text {Lower }}$, in the lower tank, and, therefore, the flow limitation is to be mitigated with increasing $h$ and $V_{\text {Lower }}$.

These experimental results clearly show that not only the pipe geometry but also tank geometry and water levels in the tanks must be taken into account when modelling characteristics of CCFL in vertical pipes.

\section{References}

[1] H. Nakamura, J. Katayama, and Y. Kukita, "Loss of Residual Heat Removal (RHR) event during PWR mid-loop operation: ROSA-IV/LSTF experiment without opening on primary loop pressure boundary," ASME FED Power Plant Transients, vol. 140, pp. 9-16, 1992.

[2] C. Yanagi, T. Nariai, T. Futatsugi, A. Tomiyama, I. Kinoshita, and M. Murase, "Countercurrent air-water tests using a scale model of a pressurizer surge line," in Proceedings of the 19th International Conference on Nuclear Engineering (ICONE1943222), 2011.

[3] G. B. Wallis, A. S. Karlin, C. R. Clark III, D. Bharathan, Y. Hagi, and H. J. Richter, "Countercurrent gas-liquid flow in parallel vertical tubes," International Journal of Multiphase Flow, vol. 7, no. 1, pp. 1-19, 1981.

[4] D. Bahrathan, G. B. Wallis, and H. J. Richter, Air Water Countercurrent Annular Flow in Vertical Tubes, EPRI NP-786, Electric Power Research Institute, 1978. 
[5] C. L. Tien and C. P. Liu, Survey on Vertical Two-Phase Countercurrent Flooding, EPRI NP-984, Electric Power Research Institute, 1979.

[6] D. J. Nicklin and J. F. Davidson, "The onset of instability in two-phase slug flow," in Proceedings of the Institute of Mechanical Engineers Symposium on Two-Phase Flow, no. 4, 1962.

[7] H. J. Richter, "Flooding in tubes and annuli," International Journal of Multiphase Flow, vol. 7, no. 6, pp. 647-658, 1981.

[8] C. P. Liu, C. L. Tien, and G. E. McCarthy, Flooding in Vertical Gas-Liquid Countercurrent Flow through Parallel Path, EPRINP-2262, Electric Power Research Institute, 1982.

[9] Y. Sudo, T. Usui, and M. Kaminaga, "Experimental study of falling water limitation under a counter-current flow in a vertical rectangular channel," JSME International Journal, Series B, vol. 34, no. 2, pp. 169-174, 1991.

[10] J. H. Jeong and N. C. No, "Experimental study of the effect of pipe length and pipe-end geometry on flooding," International Journal of Multiphase Flow, vol. 22, no. 3, pp. 499-514, 1996.

[11] F. Kaminaga, Y. Okamoto, and Y. Shibata, "Evaluation of Entrance Geometry Effect on Flooding," in Proceedings of the 1st JMSE/ASME Joint International Conference on Nuclear Engineering, vol. 95, 1991.

[12] G. B. Wallis, D. C. deSieyes, R. J. Rosselli, and J. Lacombe, Countercurrent Annular Flow Regimes for Steam and Subcooled Water in a Vertical Tube, NP-1336, Research Project 443-2, EPRI, Palo Alto, Calif, USA, 1980.

[13] D. Bharathan and G. B. Wallis, "Air-water countercurrent annular flow," International Journal of Multiphase Flow, vol. 9, no. 4, pp. 349-366, 1983.

[14] G. B. Wallis, One-Dimensional Two-Phase Flow, McGraw Hill, 1969.

[15] S. Jayanti, A. Tokarz, and G. F. Hewitt, "Theoretical investigation of the diameter effect on flooding in countercurrent flow," International Journal of Multiphase Flow, vol. 22, no. 2, pp. 307-324, 1996.

[16] S. S. Kutateladze, "Elements of the Hydraulics of Gas-Liquid System," Fluid Mechanics Soviet Research, vol. 1, no. 4, pp. 2950, 1972.

[17] M. Vijayan, S. Jayanti, and A. R. Balakrishnan, "Effect of tube diameter on flooding," International Journal of Multiphase Flow, vol. 27, no. 5, pp. 797-816, 2001.

[18] O. R. Jaiswal, S. Kulkarni, and P. Pathak, "A study on sloshing frequencies of fluid-tank system," in Proceeding of the 14th World Conference on Earthquake Engineering, 2008. 

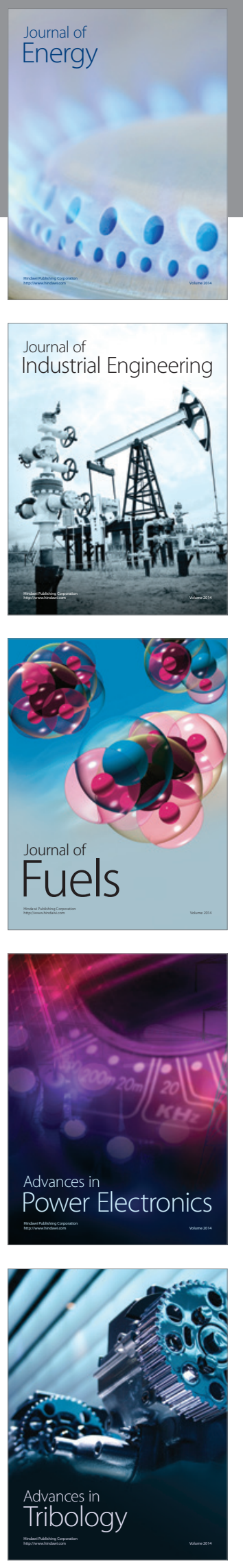
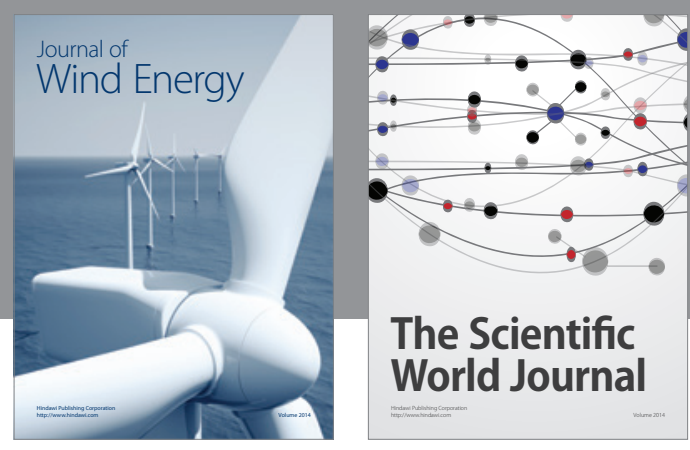

The Scientific World Journal

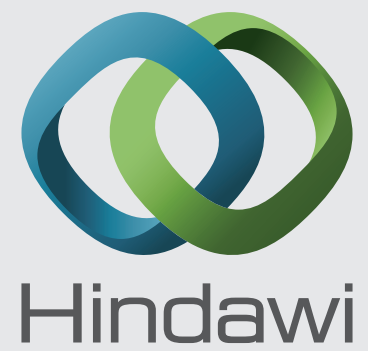

Submit your manuscripts at http://www.hindawi.com
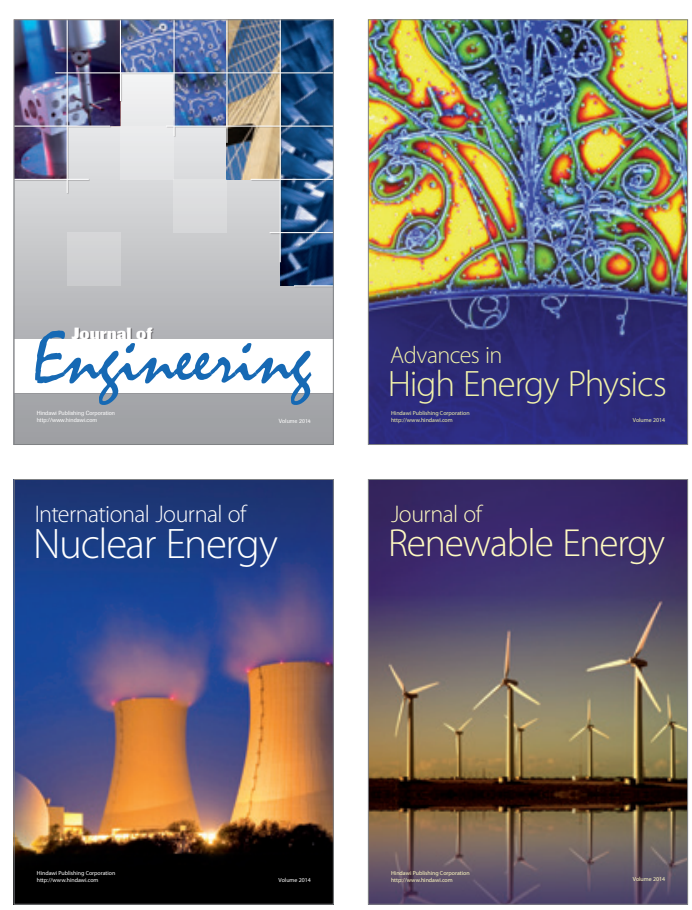

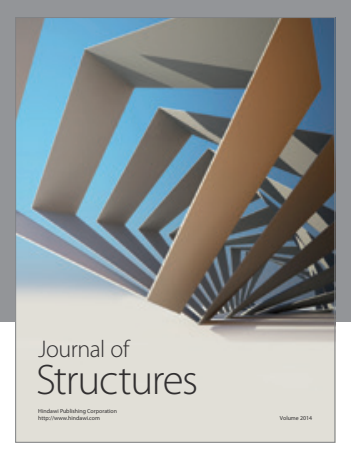

Rotating
Mechinery
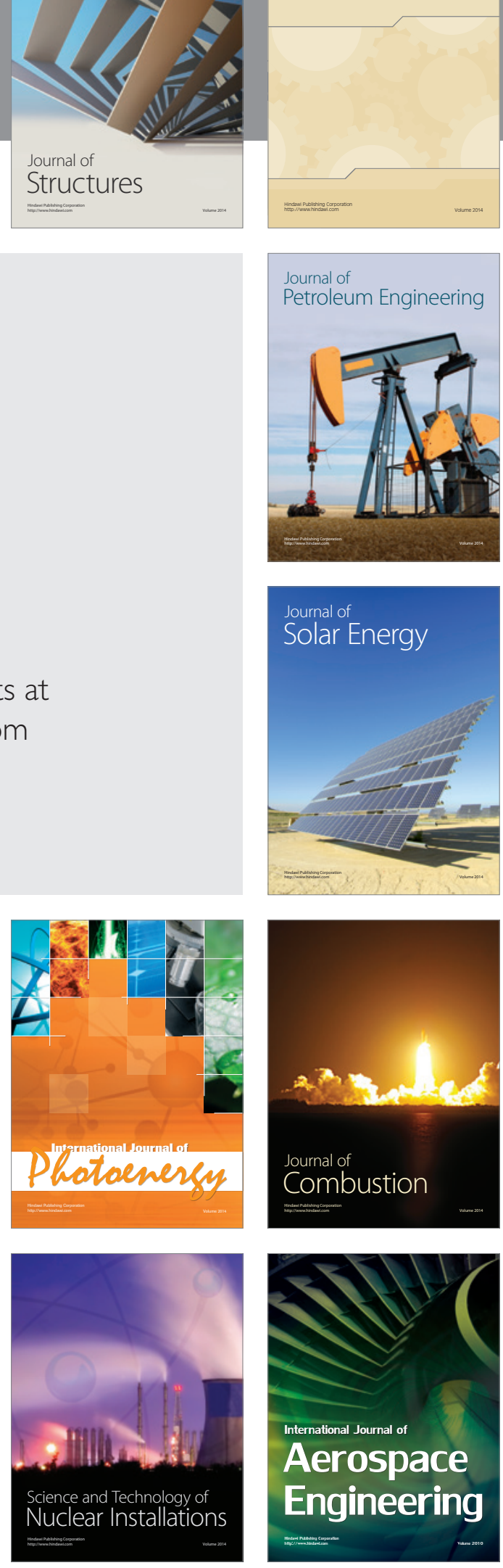